\title{
Disponibilidade de alimentos na alimentação escolar de estudantes do ensino fundamental no âmbito do PNAE, na cidade de Codó, Maranhão
}

\author{
Food availability in school menu for elementary and \\ middle school students in the context of PNAE, in Codó, Maranhão
}

\author{
Carlyanne do Nascimento Costa ${ }^{1,2,3}$, Jane de Carlos Santana Capelli ${ }^{2}$, \\ Camilla Medeiros Macedo da Rocha ${ }^{2}$, Gina Torres Rego Monteiro ${ }^{3}$
}

\begin{abstract}
Resumo
Introdução: A alimentação no âmbito do Programa Nacional de Alimentação Escolar (PNAE) permite atender às necessidades nutricionais de estudantes no ambiente escolar por meio da alimentação saudável e balanceada, contendo também alimentos da agricultura familiar (AF). O estudo objetiva descrever as preparações ofertadas na alimentação de estudantes e os alimentos oriundos da AF no PNAE do município de Codó, no Maranhão. Método: Trata-se de um estudo descritivo, de base escolar, contemplando as escolas de ensino fundamental da rede pública da área urbana, vinculadas ao PNAE, entre março e junho de 2015. Resultados: Todas as escolas $(n=26)$ participaram do estudo. Das preparações oferecidas, $16 \%$ atenderam ao cardápio planejado. Constatou-se a presença de pelo menos um alimento oriundo da AF em mais da metade das escolas visitadas. Conclusão: A maioria das preparações oferecidas não atendeu ao cardápio planejado. Os alimentos oriundos da AF foram: iogurte, bolo, frutas, feijão, arroz, entre outros.
\end{abstract}

Palavras-chave: alimentação; alimentação escolar; saúde coletiva; nutrição.

\section{Abstract}

Introduction: Meals under the National School Feeding Program (PNAE) allows to meet the nutritional needs of students in the school environment through healthy and balanced diet containing food from family farms (FF). This study aimed to describe the preparations offered in students meals and foods coming from family farms in the PNAE of the municipality of Codó/MA. Method: a descriptive, school-based study, including all elementary and middle schools of the urban area, linked to PNAE, between March and June 2015. Results: all schools $(n=26)$ participated in the study. About $16 \%$ of the preparations offered met the menu planned. We observed the presence of at least one food from FF in more than half of the schools visited. Conclusion: most of the preparations offered did not meet planned menu. Foods originated from the FF were: milk, cake, fruits, beans, rice, among others.

Keywords: feeding; school feeding; public health; nutrition.

1'nstituto Federal do Maranhão (IFMA), Campus Codó - Codó (MA), Brasil.

¿Universidade Federal do Rio de Janeiro (UFRJ), Campus UFRJ-Macaé - Macaé (RJ), Brasil.

${ }^{3}$ Departamento de Epidemiologia e Métodos Quantitativos em Saúde, Escola Nacional de Saúde Pública Sérgio Arouca (ENSP), Fundação Oswaldo Cruz (Fiocruz) - Rio de Janeiro (RJ), Brasil.

Trabalho realizado nas escolas públicas do ensino fundamental de Codó (MA), Brasil.

Endereço para correspondência: Jane de Carlos Santana Capelli - Curso de Nutrição, Universidade Federal do Rio de Janeiro (UFRJ), Campus UFRJ-Macaé Professor Aloisio Teixeira, Rua Aloísio da Silva Gomes, 50 - Granja dos Cavaleiros - CEP: 27930-560 - Macaé (RJ), Brasil - Email: jcscapelli@gmail.com

Fonte de financiamento: nenhuma.

Conflito de interesses: nada a declarar. 


\section{INTRODUÇÃO}

A alimentação escolar (AE) é "todo alimento oferecido no ambiente escolar, independentemente de sua origem, durante o período letivo"1, e é assegurada pela Constituição Federal, em seu artigo 208, inciso VII, que estabelece o dever do Estado com a educação pelo "atendimento ao educando, no ensino fundamental, através de programas suplementares de material didático, transporte, alimentação e assistência à saúde" ${ }^{\prime 2}$. As necessidades de alimentação, portanto, devem ser garantidas pelas escolas brasileiras na educação básica ${ }^{3}$.

A Merenda Escolar, como é mais popularmente conhecida, existe desde 1955, sendo uma ação de suplementação alimentar do governo federal no campo das políticas social e assistencial ${ }^{4}$. É considerado um dos maiores programas na área de $\mathrm{AE}$ em todo o mundo e o único programa alimentar cujo atendimento é universal ${ }^{1,3}$, visando garantir a permanência dos estudantes nas escolas e reduzir a desnutrição infantil no Brasil ${ }^{5}$. Em 1979, o programa passou a ser denominado Programa Nacional de Alimentação Escolar (PNAE), com o objetivo de atender às necessidades nutricionais dos estudantes durante sua estadia na escola, contribuindo para o crescimento, desenvolvimento, aprendizagem e rendimento escolar ${ }^{3}$.

A AE se insere no âmbito da Segurança Alimentar e Nutricional $(\mathrm{SAN})^{6}$, uma vez que um dos princípios do PNAE é a garantia do Direito Humano à Alimentação Adequada ${ }^{5}$. A SAN propõe que as políticas de estímulo ao crescimento da produção agroalimentar devam estar associadas à valorização das culturas alimentares, bem como ao enfrentamento da pobreza no meio rural e ao estímulo ao desenvolvimento local e regional ${ }^{1,6,7}$.

Nessa perspectiva, a Resolução no $26 / 2013^{7}$ estabelece que as entidades executoras (secretarias estaduais de educação, as prefeituras municipais e também as escolas federais) comprem $30 \%$ dos gêneros alimentícios oriundos da agricultura familiar (AF), objetivando fortalecer e incentivar sua produção, e do empreendedor familiar rural com dispensa de licitação. Visa ainda, entre outros pontos observados nas diretrizes do programa, favorecer uma diversidade de produtos na $\mathrm{AE}$ e estimular o consumo de alimentos da região $0^{1,8}$.

No Estado do Maranhão/Brasil, 45 municípios implantaram o PNAE, como a cidade de Codó, que, no ano de 2014, atendeu 10.413 estudantes em 60 escolas municipais situadas na zona urbana9.

A alimentação adequada na idade escolar é um tema de singular importância no campo da saúde coletiva, pois influencia o perfil de agravos à saúde nas outras fases da vida. Ainda assim, a literatura científica sobre o PNAE é escassa, não havendo publicações sobre o tema na área de estudo. Nesse contexto, o presente artigo objetivou descrever as preparações ofertadas na alimentação de estudantes e os alimentos oriundos da $\mathrm{AF}$ no PNAE do município de Codó/MA.

\section{MÉTODOS}

Trata-se de um estudo descritivo, de base escolar, realizado no município de Codó/MA, contemplando as escolas da rede de ensino fundamental da área urbana, atendidas pelo PNAE, com turmas do primeiro ao quinto ano do ensino fundamental, entre março e junho de 2015.

Codó é um município do Estado do Maranhão, localizado a 292 Km de São Luís, com uma população de 118.038 habitantes e com área ${ }^{10}$ de $4.361,341 \mathrm{Km}^{2}$. De acordo com o Censo Demográfico ${ }^{8}$, realizado pelo Instituto Brasileiro de Geografia e Estatística (IBGE), em 2010, havia 12.248 crianças entre 5 a 9 anos no município, das quais $62,36 \%$ eram residentes na zona urbana ${ }^{11}$.

A Coordenação de Alimentação Escolar, que está situada na Secretaria Municipal de Educação (Semed), forneceu à pesquisadora uma listagem com a relação das escolas da rede pública do ensino fundamental vinculadas ao PNAE, a localização e o contato. Além disso, também forneceu o cardápio planejado (com as preparações/dia da semana) por seu quadro técnico de nutricionistas.

Foram incluídas no estudo todas as 26 escolas de ensino fundamental da área urbana, que atenderam estudantes na faixa etária entre 6 e 10 anos, matriculados do primeiro ao quinto ano, em 2015. Esse grupo concentra cerca de $80 \%$ dos estudantes atendidos pelo PNAE; os demais (20\%) estão matriculados em escolas da área rural do município?.

As variáveis estudadas foram: dia da visita às escolas, grupos de alimentos presentes no cardápio planejado/dia da semana, tipos de preparações no cardápio planejado, tipos de preparações oferecidas pela escola, grupos de alimentos oferecidos nas preparações da escola e alimentos ofertados, líquidos oferecidos e alimentos oriundos da AF.

Estabeleceram-se como grupos alimentares aqueles propostos pelo Guia Alimentar da População Brasileira ${ }^{12}$ (doravante citado como Guia), como apresentado no Quadro 1.

Quadro 1. Grupos alimentares segundo o Guia Alimentar da População Brasileira

\begin{tabular}{|c|l|}
\hline Categoria & \multicolumn{1}{|c|}{ Grupo de alimentos* } \\
\hline Grupo 1 & Arroz, pães, massas, batata e mandioca. \\
\hline Grupo 2 & Verduras e legumes. \\
\hline Grupo 3 & Frutas. \\
\hline Grupo 4 & Carnes, peixes e ovos. \\
\hline Grupo 5 & Feijões. \\
\hline Grupo 6 & Leites, queijos e iogurtes. \\
\hline Grupo 7 & Óleos e gorduras. \\
\hline Grupo 8 & Açúcares e doces. \\
\hline Grupo 9 & Líquidos (refrescos e sucos de frutas). \\
\hline
\end{tabular}

${ }^{*}$ Grupos de alimentos considerados como possibilidade de troca nas preparações/ alimentos presentes no cardápio planejado pelo quadro técnico de nutricionistas da Coordenação de Alimentação Escolar da Secretaria Municipal de Educação de Codó/MA. Fonte: Brasil ${ }^{12}$ 
Quanto aos instrumentos do estudo, elaborou-se um formulário adaptado dos capítulos descritos nas Resoluções do Fundo Nacional de Desenvolvimento da Educação (FNDE) ${ }^{3,7}$, contendo questões semiestruturadas.

Para a coleta de dados, após a autorização da Semed, uma pesquisadora previamente treinada fez contato inicial com a direção de cada escola para apresentar o projeto e, com posterior aprovação, agendar uma visita à cozinha, no turno da manhã, no dia da semana estabelecido pela diretora, com a finalidade de observar os alimentos utilizados e as preparações elaboradas na alimentação dos escolares. Nas visitas, a pesquisadora apresentava o termo de consentimento livre e esclarecido (TCLE) à diretora e, após a assinatura, era encaminhada à cozinha da escola. No período de quatro meses, cada escola foi visitada duas vezes, em semanas diferentes.

Realizou-se uma análise descritiva por meio de frequência absoluta e relativa das variáveis categóricas. As proporções das preparações oferecidas na escola foram comparadas com aquelas previstas nos cardápios elaborados pelo quadro técnico de nutricionistas da Semed. Definiu-se como "Atende" quando as preparações oferecidas na escola seguiam a proposta do cardápio elaborado e como "Não Atende" quando as preparações eram diferentes do cardápio proposto. Contudo, mesmo sendo "Não Atende", definiu-se o termo "De Acordo" para preparações cujos alimentos (pelo menos dois) pudessem ser trocados na lista de substituição por outros alimentos de seus respectivos grupos alimentares ${ }^{12}$, sendo considerado o termo "Não de Acordo", se não atingisse tal critério.

O projeto de pesquisa seguiu as regras previstas pela Resolução no 466/2012 do Conselho Nacional de Saúde/Ministério da Saúde ${ }^{13}$, sendo submetido ao Comitê de Ética em Pesquisa da Escola Nacional de Saúde Pública Sérgio Arouca/Fiocruz, com protocolo CAAE 38596614.4.0000.5240, e aprovado.

\section{RESULTADOS}

Das 26 escolas contatadas, $100 \%$ participaram do estudo na primeira visita, e $92,3 \%(n=24)$, na segunda visita, pois duas escolas estavam em reforma, sem previsão de término, quando houve o contato para agendar a segunda visita.

$\mathrm{O}$ estudo mostrou que o cardápio elaborado para a $\mathrm{AE}$ do município de Codó/MA é padrão para todas as unidades de ensino, com periodicidade semestral.

De acordo com o Quadro 2, pode-se observar que, às segundas-feiras, a preparação contém os grupos de alimentos 1, 2 e 4, os quais são fontes de carboidratos, proteínas, sais minerais e vitaminas. Às quartas, os alimentos do grupo 1 (e outros grupos) podem ser substituídos por outros alimentos do grupo 1 (e grupo 9), sendo fonte de carboidratos, proteínas, sais minerais e vitaminas. Às terças, quintas e sextas-feiras, a preparação contém os grupos 1 e 6 , fornecendo proteínas, cálcio e carboidratos. O grupo 7 está embutido em todas as preparações previstas no cardápio de segunda e quarta-feira, uma vez que podem levar óleo, azeite, manteiga ou margarina.

No cardápio planejado, considera-se que a elaboração das refeições, pautada na proposta da alimentação saudável, não foi plenamente atendida, uma vez que o grupo 5 , ou seja, o grupo das leguminosas, não foi previsto pelo quadro técnico de nutricionistas (Figura 1).

Ao comparar as preparações do cardápio planejado com as preparações oferecidas nas escolas (Figura 2), na primeira e segunda visita, detectou-se que somente 15,4 e $16,7 \%$ das preparações atenderam ao cardápio planejado, respectivamente. Entre as preparações que não estavam previstas no cardápio planejado, apenas 9,1\% dos casos na primeira visita e $15 \%$ na segunda estavam "De Acordo" com os mesmos grupos alimentares propostos no Guia ${ }^{12}$.

Os alimentos e as preparações observados na AE foram: milho cozido; macaxeira cozida; vitamina de batata-doce; frutas (banana e mamão); arroz com carne; macarrão com sardinha; frutas (melancia e banana); suco com biscoito; achocolatado com biscoito; iogurte (bebida láctea adoçada) com bolo (caseiro, sem cobertura e calda); arroz com feijão e sardinha; arroz com macarrão e sardinha; arroz com abóbora, salada e sardinha; torrada com suco de goiaba; macaxeira cozida com iogurte e suco com bolo.

Os alimentos utilizados para a substituição daqueles previstos nas preparações indicadas no cardápio planejado estavam de acordo com a safra, cultura alimentar da região e hábitos alimentares, atendendo à proposta de alimentação saudável e adequada à população ${ }^{14}$.

Em relação aos alimentos oriundos da AF, detectou-se que havia pelo menos um alimento em $50 \%$ das preparações oferecidas na primeira visita e em $79 \%$ na segunda (Figura 3). Eram provenientes da AF: iogurte (bebida láctea adoçada), leite, batata, milho, macaxeira, arroz, frutas (banana, mamão e melancia), abóbora, feijão, bolo (caseiro, sem cobertura e recheio) e polpa de frutas.

Quadro 2. Cardápio semanal previsto para o primeiro semestre de 2015, elaborado pelo quadro técnico de nutricionistas da Coordenação de Alimentação Escolar da Secretaria Municipal de Educação de Codó/MA

\begin{tabular}{|l|l|}
\hline Dia da semana & \multicolumn{1}{c|}{ Cardápio } \\
\hline Segunda-feira & Arroz com macarrão, sardinha e salada verde. \\
\hline Terça-feira & Leite com flocão de milho. \\
\hline Quarta-feira & $\begin{array}{l}\text { Arroz com carne, legumes* e frutas* ou Suco } \\
\text { com biscoito. }\end{array}$ \\
\hline Quinta-feira & Achocolatado com pão/biscoito. \\
\hline Sexta-feira & Iogurte com biscoito. \\
\hline
\end{tabular}

${ }^{\star}$ De acordo com a safra 


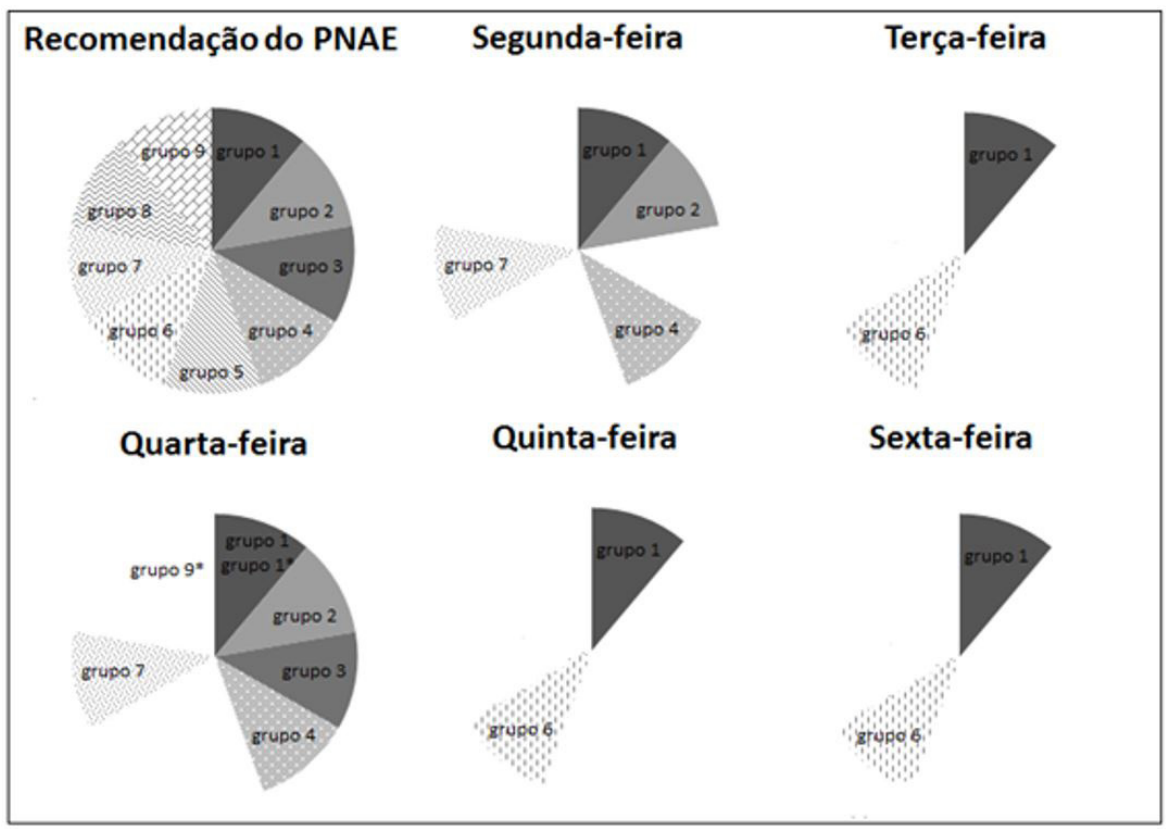

Figura 1. Grupos de alimentos propostos no Guia Alimentar da População Brasileira, de 2005, segundo recomendação do Programa Nacional de Alimentação Escolar, encontrados nas preparações presentes, de acordo com os dias da semana, no cardápio planejado pelo quadro técnico de nutricionistas da Coordenação da Alimentação Escolar da Secretaria Municipal de Educação, em Codó/MA, 2015. * Quarta-feira: Grupos $1^{*}$ e $9^{*}$ como refeição substituta da primeira opção de refeição

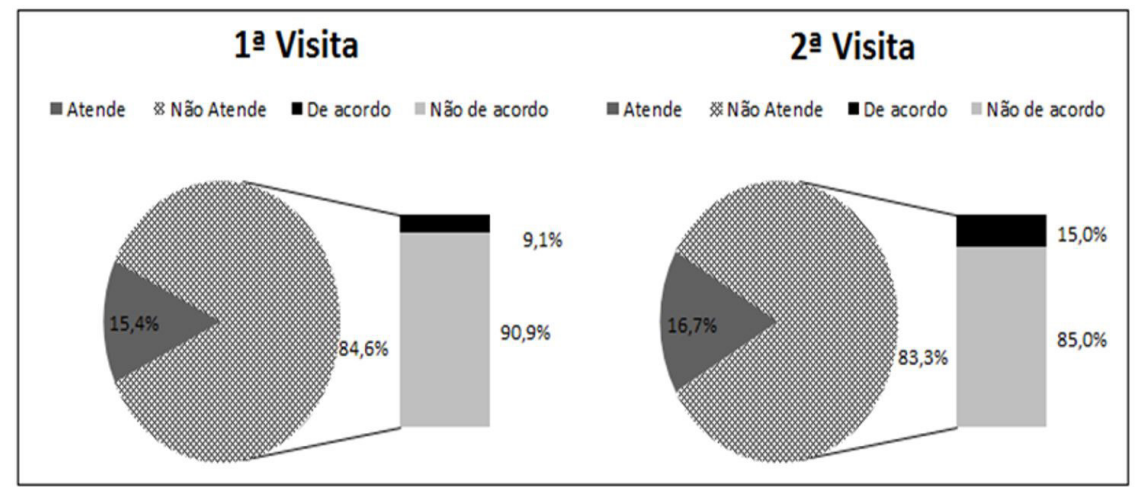

Figura 2. Preparações oferecidas nas escolas quando da primeira $(=26)$ e segunda $(n=24)$ visita, segundo atendimento ao cardápio planejado pelo quadro técnico de nutricionistas da Coordenação de Alimentação Escolar da Secretaria Municipal de Saúde, e se as substituições estavam de acordo com os grupos alimentares propostos no Guia Alimentar da População Brasileira, de 2005, em Codó/MA, 2015

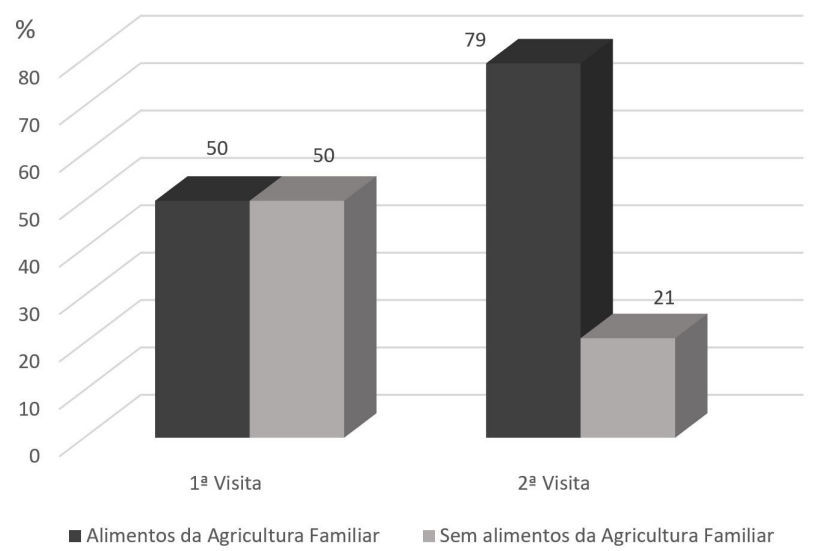

Figura 3. Distribuição percentual de alimentos oriundos da agricultura familiar, nas preparações da alimentação escolar, na primeira $(n=26)$ e segunda $(n=24)$ visita às escolas, em Codó/MA, 2015

\section{DISCUSSÃO}

Os resultados revelam que apenas $15,4 \%$ (na primeira visita) e $16,7 \%$ (na segunda visita) das preparações atenderam, ou seja, eram iguais, ao cardápio planejado pelo quadro técnico de nutricionistas da Coordenação da Alimentação Escolar da Semed. Encontrou-se uma diversidade de produtos ofertados nas escolas visitadas oriundos da AF.

Observou-se um cardápio padrão (apresentando refeições, como almoço e lanches), elaborado para todo o semestre, em todas as escolas, com variedades de preparações no decorrer da semana (Quadro 2), todavia sem atender à proposta de alimentação saudável em três dos cinco dias úteis da semana, uma vez que nesses dias as preparações possuíam somente alimentos dos grupos 1 e 6 (grupo 1: arroz, pães, massas, batata e mandioca; grupo 6: leites, queijos e iogurtes). 
O estudo detectou também que, no cardápio elaborado pelas nutricionistas, não foi previsto o grupo 5 (leguminosas, como os diferentes tipos de feijões), importantes fontes de proteínas, fibras, vitaminas do complexo B e minerais, como ferro e zinco ${ }^{14}$. Verificou-se que apenas uma escola visitada ofereceu uma preparação contendo a combinação "feijão com arroz", que juntos contêm boas fontes de aminoácidos, além de serem muito populares no território brasileiro. Nas demais escolas visitadas, as preparações que continham somente arroz (sem o feijão) apresentavam o grupo das carnes, o que permite uma oferta de aminoácidos de alto valor biológico ${ }^{12}$.

Já a oferta de frutas, verduras e legumes no cardápio constava nas preparações em somente dois dias da semana. Pela Resolução $n^{\circ} 26 / 2013^{7}$, devem-se ofertar frutas, verduras e legumes pelo menos três porções na semana, como previsto no cardápio elaborado. O estudo não quantificou as porções oferecidas nas preparações, todavia, para fins de alimentação balanceada e saudável, o ideal seria que esses alimentos compusessem, diariamente, as refeições da alimentação do escolar, uma vez que são fontes de nutrientes necessários ao crescimento e desenvolvimento do estudante nessa faixa etária ${ }^{15}$.

Outra categoria que apresentou uma quantidade apreciável de alimentos encontrados foi a de ultraprocessados, como achocolatado, bolo e iogurte, que deveriam ser evitados, pois são ricos em gorduras ou açúcares e comumente apresentam elevada concentração de sódio. Além disso, possuem poucas fibras, que são componentes relevantes para a prevenção de doenças do coração, diabetes e vários tipos de câncer. A elevada quantidade de calorias por grama constitui um dos principais fatores que desregulam o balanço de energia e aumentam o risco de obesidade ${ }^{12,14}$.

O presente estudo verificou que os alimentos utilizados nas preparações dos estudantes se enquadram nas quatro categorias recomendadas pelo novo Guia, definidos de acordo com o tipo de processamento realizado durante sua produção, tais como: in natura ou alimentos minimamente processados; óleos, gorduras, sal e açúcar; alimentos processados e alimentos ultraprocessados. É importante que a categoria in natura ou alimentos minimamente processados constitua a base da $\mathrm{AE}$, por ser nutricionalmente balanceada, saborosa, apropriada e promotora de um sistema alimentar social e ambientalmente sustentável ${ }^{14,15}$.

A AE é considerada uma importante política pública, uma vez que vai interferir positivamente no processo de aprendizagem e rendimento do estudante, por meio da oferta de refeições que atendam às suas necessidades nutricionais diárias de, no mínimo, 15\% durante a sua permanência na escola. Para tal, o FNDE, responsável pelo PNAE, estabeleceu que o profissional responsável pela elaboração de cardápios deve ser o nutricionista, que deve considerar critérios técnicos para a escolha de alimentos apropriados, levando em conta a composição química e a compatibilidade entre os ingredientes, possibilitando a combinação de refeições variadas que atendam à vocação agrícola e à cultura alimentar local. Dessa forma, os cardápios devem prever, obrigatoriamente, a utilização de $70 \%$ dos recursos federais na aquisição de produtos básicos, priorizando os alimentos in natura ou classificados como minimamente processados ${ }^{16,17}$. Para o PNAE, os demais $30 \%$ podem ser utilizados na compra de produtos industrializados, justificados pela heterogeneidade da execução nas diferentes localidades, pelas condições de infraestrutura e de acesso às escolas. Assim, cada município poderá comprar gêneros alimentícios segundo sua cultura, diversidade, disponibilidade e oferta de alimentos. Neste estudo, segundo o quadro técnico de nutricionistas do PNAE de Codó/MA, os alimentos comprados seguem os percentuais sugeridos na Resolução n 26/20137.

Ao elaborar o cardápio, o nutricionista deve excluir os alimentos não saudáveis, como doces, alimentos açucarados e lanches com excesso de gorduras, apesar de eles serem bem aceitos e consumidos diariamente por muitos estudantes e permitido por lei que estejam na $\mathrm{AE}$. Entende-se que a presença de frutas da safra ou de hortaliças e legumes da região permite a promoção e formação de hábitos alimentares mais saudáveis, bem como o desenvolvimento sustentável ${ }^{15}$.

A Resolução no $26 / 2013^{7}$ não determina a periodicidade de elaboração do cardápio. Em Codó/MA, o cardápio elaborado pelo quadro técnico de nutricionistas da Semed era recomendado para o semestre inteiro. Também em Santa Catarina, Lima e Sousa ${ }^{18}$ detectaram que o cardápio elaborado pelo quadro técnico de nutricionistas era semestral. Contudo, os autores também observaram que o cardápio era proposto um dia antes, ou no mesmo dia do fornecimento dos alimentos aos escolares, tendo como justificativa a disponibilidade de produtos, o que favorecia a elaboração de cardápios diferentes daqueles planejados em nível central.

O estudo identificou também a presença frequente de pelo menos um alimento proveniente da $\mathrm{AF}$ em 50 e $79 \%$ das preparações, na primeira e segunda visita, respectivamente, diferentemente dos achados em pesquisa realizada sobre o planejamento dos cardápios para escolas públicas municipais de Florianópolis/SC e Belém/ $/ \mathrm{PA}^{19}$, na qual os autores verificaram a inexistência da aquisição direta de alimentos da AF e/ou do empreendedor familiar rural para AE. Segundo os autores, em Belém/PA, os produtores da região não tinham estrutura suficiente ou não atendiam à demanda das escolas, enquanto em Florianópolis/SC os produtores habilitados não apresentaram a documentação necessária completa ${ }^{19}$. 
É fundamental que os cardápios da $\mathrm{AE}$ contemplem gêneros alimentícios básicos, respeitando as referências nutricionais, os hábitos alimentares, a cultura alimentar da localidade, e sejam pautados na sustentabilidade, sazonalidade e diversificação agrícola da região e na alimentação saudável e adequada ${ }^{7}$.

No presente estudo, observou-se uma diversidade de produtos alimentícios oferecidos, totalizando pelo menos 12 itens encontrados nas escolas. Entre os produtos oriundos da AF, houve uma diversidade no fornecimento de produtos regionais, tais como: milho verde, macaxeira, melancia, feijão verde e alface.

Ribeiro et al. ${ }^{20}$, em estudo sobre a participação da AF no PNAE em municípios do Rio Grande do Sul, após coleta de dados na Empresa de Assistência Técnica e Extensão Rural do RS (Emater), Secretaria de Desenvolvimento Agrário e Secretaria de Educação dos municípios, relataram uma grande diversidade de produtos agrícolas que podiam ser fornecidos para as escolas (aproximadamente 50 itens). O grupo das hortaliças apresentou maior expressão por ser uma atividade habitual realizada pelos agricultores e por não necessitar de grandes adequações, como as certificações que são necessárias no caso de outros produtos, por exemplo, embutidos e de panificação ${ }^{20}$.

Toyoyoshi et al. ${ }^{21}$, avaliando a aquisição de gêneros alimentícios advindos da AF nos municípios contemplados com o "Prêmio Gestor Eficiente da Merenda Escolar de 2011", utilizando o formulário de inscrição enviado pelos municípios e o relatório elaborado pela equipe técnica da organização não governamental (ONG) Ação Fome Zero, constataram que $68 \%$ dos municípios listaram a compra de frutas e polpa de frutas da AF como os alimentos mais adquiridos localmente. Os autores ainda ressaltam que esse achado sugere que os municípios estão seguindo as normas que regem o PNAE no que tange ao uso de alimentos variados, respeitando a cultura e as tradições da região $0^{21}$.

Os gêneros in natura e que são característicos da identidade alimentar local, ou seja, em Codó, no presente estudo, como a macaxeira, por exemplo, podem fazer parte do cardápio escolar, pois o Guia recomenda a utilização de raízes e tubérculos por seu conteúdo de carboidratos complexos e por serem compostos por proteínas e vitaminas do complexo B, além de outras vitaminas, minerais, ácidos graxos essenciais e fibras alimentares ${ }^{14,22}$.

Pesquisas mostram que, apesar de alguns municípios fornecerem alimentos orgânicos para $\mathrm{AE}$, muitas dificuldades ainda são enfrentadas. Santos et al. ${ }^{23}$ realizaram um estudo sobre a inserção dos alimentos orgânicos provenientes da AF na AE em territórios do Rio Grande do Sul, e os resultados apontaram que os gestores municipais, quando questionados sobre a dificuldade de inserção de alimentos orgânicos na $\mathrm{AE}$, ressaltaram como causas: produção local insuficiente (59\%), falta de certificação $(31,1 \%)$, elevado custo $(4,9 \%)$, desorganização dos órgãos envolvidos (3,3\%) e agricultura convencional em fase de transição para orgânica $(1,6 \%)$.

Silva e Sousa ${ }^{24}$, em estudo realizado sobre alimentos orgânicos na AE em Santa Catarina, relataram que a maioria dos agricultores e cooperativas não tinha certificação de seus produtos e enfrentava problemas de produção, revelando a necessidade de apoio técnico.

Também em Codó/MA, os alimentos orgânicos não estão contemplados na AE. De acordo com a coordenadora do PNAE, para sanar essa questão, os órgãos federais e estaduais estão verificando a possibilidade de facilitar o acesso ao selo de certificação para orgânicos aos agricultores que cultivam esses alimentos no município.

O presente estudo apresenta limitações, como não ter realizado a análise das preparações quanto às recomendações nutricionais e porções servidas. Entretanto, esse não era seu objetivo devido a dificuldades operacionais, como o curto tempo para a realização da pesagem dos alimentos nas escolas, bem como a análise segundo nutrientes específicos. Outra limitação foi a visita à escola ter sido definida pela direção, o que poderia interferir positivamente na elaboração da preparação a ser oferecida no dia da visita. No entanto, as visitas abarcaram diferentes dias da semana, e, de acordo com os resultados obtidos, entendeu-se que essa possibilidade não impactou na melhoria no tipo de preparação ofertada, permitindo, portanto, o conhecimento da AE no conjunto das escolas da rede pública de ensino fundamental I de Codó. Entre os pontos fortes deste estudo, está a observação local da alimentação oferecida em todas as escolas públicas que atendiam crianças do primeiro ao quinto ano de uma cidade de médio porte. Os resultados obtidos trazem informações importantes que foram encaminhadas à Semed, possibilitando adequar a alimentação dos escolares segundo as diretrizes da PNAE.

\section{CONCLUSÃO}

Conclui-se que somente cerca de 1/6 das preparações atendeu ao cardápio planejado, que a substituição dos alimentos não foi realizada de acordo os grupos de alimentos proposto pelo Guia Alimentar e que, pelo menos, um alimento oriundo da AF estava presente em $50 \%$ das preparações oferecidas aos estudantes, quais sejam: iogurte, leite, batata, milho, macaxeira, arroz, frutas (banana, mamão e melancia), abóbora, feijão, bolo e polpa de frutas.

É importante que esforços sejam dispendidos para a oferta adequada e rotineira de alimentos oriundos da $\mathrm{AF}$ nos cardápios elaborados na $\mathrm{AE}$ para garantir a alimentação saudável diária aos escolares do município de Codó/MA. 


\section{REFERÊNCIAS}

1. Brasil. Ministério da Educação. Fundo Nacional de Desenvolvimento da Educação. Lei no 11.947 de 16 de junho de 2009. Dispõe sobre o atendimento da alimentação escolar e do Programa Dinheiro Direto na Escolar aos alunos da educação básica; altera as Leis nos 10.880, de 9 de junho de 2004, 11.273, 6 de fevereiro de 2006, 11.507, de 20 de julho de 2007; revoga dispositivos da medida provisória n ${ }^{\circ} 2.178-36$, de 24 de agosto de 2001, e a Lei $n^{\circ} 8.913$, de 2 de julho de 1994; e dá outras providências. Diário Oficial da União [Internet], Brasília, 2009 [citado em 2014 Maio 12]. Disponível em: http://www.planalto.gov.br/ccivil_03/ato2007/2009/lei/11947.htm.

2. Brasil. Constituição da República Federativa do Brasil. Brasília: Senado Federal; 1988.

3. Brasil. Ministério da Educação. Fundo Nacional de Desenvolvimento da Educação. Resolução CD/FNDE no 38, de 16 de julho de 2009. Dispõe sobre o atendimento da alimentação escolar aos alunos da educação básica no Programa Nacional de Alimentação Escolar - PNAE. Diário Oficial da União [Internet], Brasília, 2009 [citado em 2014 Maio 12]. Disponível em: http://www.fnde.gov.br/index.php/programas-alimentacaoescolar.

4. Spinelli MAS, Canesqui AM. O programa de alimentação escolar no estado de Mato Grosso: da centralização à descentralização (1.979-1.995). Rev Nutr. 2002;15(1):105-17. http://dx.doi.org/10.1590/S1415-52732002000100011.

5. Burity V, Franceschini T, Valente F, Recine E, Leão M, Carvalho MF. Direito humano à alimentação adequada no contexto da segurança alimentar e nutricional. Brasília: Abrandh; 2010. 204 p.

6. Brasil. Lei Orgânica de Segurança Alimentar e Nutricional. Lei $N^{\circ} 11.346$ de 15 de setembro de 2006. Cria o Sistema Nacional de Segurança Alimentar e Nutricional - SISAN com vistas em assegurar o direito humano à alimentação adequada e dá outras providências. Diário Oficial da União [Internet], Brasília, 2006 [citado em 2015 Set 06]. Disponível em: http:// www.planalto.gov.br/ccivil_03/_ato20042006/2006/lei/111346.htm.

7. Brasil. Ministério da Educação. Fundo Nacional de Desenvolvimento da Educação. Resolução № 26 de 17 de Junho de 2013. Dispõe sobre o atendimento da alimentação escolar aos alunos da educação básica no âmbito do Programa Nacional de Alimentação escolar (PNAE). Diário Oficial da União [Internet], Brasília, 2013 [citado em 2015 Maio 12]. Disponível em: http://www.educacao.sp.gov.br/a2sitebox/arquivos/documentos/958.pdf.

8. Saraiva EB, Silva ANF, Sousa AA, Cerqueira G, Chagas CMS, Toral N Panorama da compra de alimentos da agricultura familiar para o programa nacional de alimentação escolar. Cien Saude Colet. 2013;18(4):927-935.

9. Instituto Brasileiro de Geografia e Estatística. Censo 2010: características gerais da população do município de Codó. Rio de Janeiro: IBGE; 2010 [citado em 2015 Nov. 29]. Disponível em: http://www.censo2010.ibge.gov. br.

10. Instituto Brasileiro de Geografia e Estatística. Censo 2010. Cidades@: Maranhão - Codó. Rio de Janeiro: IBGE [citado em 2017 Mar. 16]. Disponível em: http://cidades.ibge.gov.br/xtras/perfil.php?lang=\&codmun=210330\& search=maranhao $\mid$ codo.

11. Codó. Prefeitura Municipal. Prefeitura. 2014 [citado em 2014 Mar. 17]. Disponível em: http://www.codo.ma.gov.br.

12. Brasil. Ministério da Saúde. Secretaria de Atenção à Saúde. CoordenaçãoGeral da Política de Alimentação e Nutrição. Guia alimentar para a população brasileira: promovendo a alimentação saudável. Brasília: Ministério da Saúde; 2005. 236 p. (Série A: Normas e Manuais Técnicos).

13. Brasil. Ministério da Saúde. Conselho Nacional de Saúde. Resolução no 466 de 12 de dezembro de 2012. Diário Oficial da União [Internet], Brasília, 2012 [citado em 2015 Ago. 11]. Disponível em: http://conselho.saude.gov. br/resolucoes/2012/Reso466.pdf.

14. Brasil. Ministério da Saúde. Secretaria de Atenção à Saúde. Departamento de Atenção Básica. Guia alimentar para a população brasileira. 2. ed. Brasília: Ministério da Saúde; 2014. 156 p.

15. Brasil. Ministério da Educação. Secretaria de Educação Básica. Alimentação saudável e sustentável. Brasília: Universidade de Brasília; 2007 [citado em 2015 Out 08]. Disponível em: http://portal.mec.gov.br/seb/arquivos/pdf/ profunc/alimet_saud.pdf.

16. Belik W. Políticas públicas, pobreza rural e segurança alimentar. In: Fagnari E, Pochman M, organizadores. Mercado de trabalho, relações sindicais, pobreza e ajuste fiscal. São Paulo; 2007. (Debates Contemporâneos: Economia Social e do Trabalho).

17. Takagi MA. A implantação da política de segurança alimentar e nutricional no Brasil: seus limites e desafios [tese]. Campinas: Universidade Estadual de Campinas, Instituto de Economia; 2006.

18. Lima EE, Sousa AA. Alimentos orgânicos na produção de refeições escolares: limites e possibilidades em uma escola pública em Florianópolis. Rev Nutr. 2011;24(2):263-27. http://dx.doi.org/10.1590/S1415-52732011000200007.

19. Gabriel CG, Costa LCF, Calvo MCM, Vasconcelos FAG. Planejamento de cardápios para escolas públicas municipais: reflexão e ilustração desse processo em duas capitais brasileiras. Rev Nutr. 2012;25(3):363-72. http:// dx.doi.org/10.1590/S1415-52732012000300006.

20. Ribeiro ALP, Ceratti S, Broch DT. Programa Nacional de Alimentação Escolar (PNAE) e a participação da agricultura familiar em municípios do Rio Grande do Sul. Rev Gest Desenvolv Contexto. 2013;1(1):36-49.

21. Toyoyoshi JY, Oliveira R, Santos MSN, Galisa MS, Galante AP. Avaliação da aquisição de gêneros alimentícios provenientes da agricultura familiar para alimentação escolar. O mundo da Saúde. 2013;37(3):329-35. http:// dx.doi.org/10.15343/0104-7809.2013373329335.

22. Marques AA, Fernandes MGM, Leite IN, Viana RT, Gonçalves MCR, Carvalho AT. Reflexões de agricultores familiares sobre a dinâmica de forneciento de seus produtos para alimentação escolar: o caso de Araripe, Ceará. Saude Soc. 2014;23(4):1329-41. http://dx.doi.org/10.1590/S010412902014000400017

23. Santos F, Fernandes PF, Rockett FC, Oliveira ABA. Avaliação da inserção de alimentos orgânicos provenientes da agricultura familiar na alimentação escolar, em municípios dos territórios rurais do Rio Grande do Sul, Brasil. Cien Saude Colet. 2014;19(5):1429-36. PMid:24897208. http://dx.doi. org/10.1590/1413-81232014195.14982013.

24. Silva APF, Sousa AA. Alimentos orgânicos da agricultura familiar no programa nacional de alimentação escolar no estado de Santa Catarina, Brasil. Rev Nutr. 2013;26(6):701-14. http://dx.doi.org/10.1590/S141552732013000600009 